\title{
A RESILIENCIA E O MORAR NA RUA: ESTUDO COM MORADORES DE RUA - CRIANÇA E ADULTOS NA CIDADE DE SÃO PAULO
}

\section{RESILIENCE AND HOMELESSNESS: A STUDY ON HOMELESS ADULTS AND CHILD - IN THE CITY OF SÃO PAULO}

Aparecida Magali de Souza Alvarez ${ }^{1}$ Cornélio Pedroso Rosenburg ${ }^{2}$

ALVAREZ, A. M. S.; ROSENBURG, C. R A resiliência e o morar na rua: estudo com moradores de rua - criança e adultos - na cidade de São Paulo. Rev. Bras. Cresc. Desenv. Hum., São Paulo, 9(1), 1999.

Resumo: O presente trabalho consistiu em aplicar a categoria Resiliencia no estudo de ex-moradores de lua da região central de São Paulo, que buscaram um outro modo de vida, no sentido de reconhecer a contribuição que esse conceito pode dar ao equacionamento de ações de saúde, em particular da saúde mental, voltadas às populações de rua, no contexto das metrópoles brasileiras. No estudo de caso, foram selecionados quatro adultos e uma criança, egressos de um grupo de moradores de nua de um bairro central da cidade de São Paulo, que, do ponto de vista investigativo, foram considerados como possíveis resilientes, ou seja, portadores de capacidade humana de fazer frente às adversidades da vida, superá-las e sairem delas fortalecidos ou, inclusive, transformados. Utilizando entrevistas abertas e semi-estruturadas, fotografias, registros no diário de campo e técnicas de observação, procedeu-se a uma descrição etnográfico da moradia e do modo de morar atual e anterior dos sujeitos participantes do estudo, assim como de suas características psíquicas e sua interação com o meio em que vivem ou viveram. A partir do reconhecimento da trajetória empreendida por eles, estes foram considerados positivamente como resilientes, com base nos conceitos heurísticos "busca de sentido" e "pontos fixos" internos e provenientes do entorno identificados nos sujeitos. Finalmente, reconhece-se a importância do conceito de resiliência em estudos desta natureza e a necessidade de difusão do mesmo para sua efetiva aplicação na área de Saúde Pública.

Palavras-chave: Resiliência; morador de rua; saúde mental; Saúde Pública.

\section{INTRODUÇÃO}

Não há estudos conclusivos no Brasil sobre o número de pessoas que moram nas ruas. Essas populações de moradores de rua, que têm aumentado constantemente, submetidas à situações de vida adversas, têm se constituído um problema, alvo de preocupações e ações, no âmbito da Saúde Pública.
RABINOVICH (1996) categorizou os moradores "sem casa" de São Paulo em cinco tipos: nômades, assentados, caverna, selvagens e neo-nômades, denominações que procuravam corresponder a aspectos físicos e vivenciais destes moradores. "Selvageim" foi a auto-denominação de um deles para as pessoas que não construíam "casas" e dormiarn na sarjeta.

\footnotetext{
* Este trabalho consiste em uma versão resumida da Dissertação de Mestrado apresentada à Faculdade de Saúde Publica da USP 1999. Ajuda financeira do CNPq.

1 Psicóloga, Mestre e Doutoranda em Saúde Pública, Faculdade de Saúde Pública USP, pesquisadora do Centro de Estudos do Crescimento e Desenvolvimento do Ser Humano - CDH - FSP/USP. Av. Dr. Arnaldo, 715 subsolo sala 21, SP - CEP 01246-904 Tel: 3066-7775. E-mail: magali@usp.br

2 Prof. Associado do Departamento de Saúde Materno infantil da Faculdade de Saúde Pública da Universidade de São Paulo. End:
} Av. Dr. Arnaldo, 715, 2 Andar, Depto. Saúde Materno-lnfantil. São Paulo - SP - CEP: 0124-904 Tel: (011) 3066-7702. 
Em 1993 entramos em contato com essa categoria - "selvagens urbanos" - acompanhando um grupo de pessoas que levavam "sopa quente” aos moradores de rua da cidade de São Paulo.

Encontramos um grupo de pessoas sem laços de parentesco, que "moravam" na calçada de uma esquina e em pequena praça em frente a essa mesma esquina, no bairro da Bela Vista.

Aquecendo-se junto a uma fogueira acesa no chão de terra da pracinha, a cães e aos próprios companheiros de rua, conhecemos $\mathrm{Célia}^{3}$, grávida; seu companheiro Hélio - pai do bebê que nasceria meses depois - e outros moradores de rua (ALVAREZ, 1994), cujas trajetórias de vida passaríamos a acompanhar, através de um estudo longitudinal, ao longo de cinco anos (de 1993 a 1998).

Nesses contatos observamos que algumas dessas pessoas, contrariando as expectativas comuns para tal tipo de população - "moradores de rua"/ "selvagens urbanos" - fizeram uma transição gradativa para outro modo de vida: abandonaram o vício da bebida alcoólica, das drogas e, gradualmente, reerguendo-se das situações adversas de suas existências, empreenderam novas trajetórias. Passaram a interessar-se pelo trabalho, preocuparam-se com um lugar melhor para morar - um "barraco" precário - que foi construído próximo à maloca. Estabeleceram novos vínculos afetivos, mantendo-se em não delinquiência.

Foram considerados, do ponto de vista investigativo, como possíveis resilientes, ou seja, "portadores da capacidade humana de fazer frente às adversidades da vida, superá-las e sair delas fortalecidos ou inclusive transformados." (GROTBERG, 1996).

Objetivamos, com este estudo - focalizando os referidos sujeitos sociais e o grupo de moradores da maloca ${ }^{4}$ o aprofundamento da temática resiliência para identificação de sua possível relevância em ações de Saúde Mental/Pública, a fim de contribuir para um reequacionamento das ações que buscam atender as populações de rua. Buscamos a identificação de algumas características psíquicas dos sujeitos sociais e a compreensão da constituição tanto do seu contorno, quanto do seu diálogo com o contorno. Buscávamos, também, a identificação dos conceitos heurísticos "ponto fixo" (DAMERGIAN, 1988; ALVAREZ e cols., 1997) e "sentido da vida" (ALVAREZ,
MORAES \& RABINOVICH, 1997) trabalhados em estudos anteriores e, ainda, outros possíveis conceitos heunsticos emergentes.

CRITELLI (1996) desenvolveu seus trabalhos com base na idéia heideggeriana do "sentido da existência” - o rumo - a respeito da experiência humana da vida que é, originariamente, a experiência da fluidez constante, da mutabilidade, da angústia - referida como a experiência da inospitabilidade do mundo quando o sentido que se fazia se evade, manifestando-se o mundo nessa sua inospitabilidade.

FRANKL (1989) ao referir-se ao "sentido da vida”, anuncia que o desejo de sentido seria não só uma genuína manifestação de humanidade do homem como também um plausível indício de saúde mental, afirmando que o ser humano deve sempre "estar endereçado", apontar para qualquer coisa ou qualquer um diverso dele próprio, ou seja, um sentido a realizar, ou para outro ser humano a encontrar, para uma causa a qual consagrar-se, ou uma pessoa a quem amar. Somente na medida em que consegue viver essa auto-transcendência da existência hurnana, alguém é autenticamente homem e autenticamente "si próprio".

Ao discorrer a respeito do "ponto fixo', conceito que assume importância central neste trabalho, DAMERGIAN (1988) nos sugere que o bebé necessitaria de um ponto fixo para construir um universo, isto é, seu mundo interno, sua identidade, ou seja, o ponto fixo seria o objeto bom que lhe deve ser of erecido pelo meio (mãe ou substituia). Sem isto, não haveria a estruturação do núcleo do ego, a personalidade não se desenvolveria, a identidade não se construiria. Reflete, ainda, a respeito desse "objeto bom" ou "ponto fixo" a ser oferecido pela "mãe sociedade" a seus "filhos membros".

BOWLBY (1989) faz referências à "base segura" como um ponto central de um comportamento de cuidados e, também, a um "modelo" positivo de comportamento a ser oferecido ao bebê (BOWLBY, 1990), como base para um desenvolvimento psicológico saudável da criança, contribuindo para a formação de uma personalidade "resiliente", que seria capaz de continuar assim mesmo em circunstâncias adversas. Melanie KLEIN (1971) também propõe acerca do "modelo favorável para formar futuros relacionamentos", ligado ao processo de estruturação da personalidade.

3 Os nomes dos moradores e ex-moradores de rua focalizados neste trabalho são fictícios, observando-se, assim, ao imperativo ético do sigilo de suas identidades.

4 “Maloca”: denominação que os próprios moradores de rua atribuem ao local e ao modo de vida dos "selvagens”, significando um modo específico de viver na rua: não construção de proteção aos próprios corpos, embriaguez, mendicância, exposição a violências. 
Edith GROTBERG (1996) argumenta a respeito da possibilidade dos pais - ou outros cuidadores - de promover - ou não - a resiliência em suas crianças, através do tipo de cuidados que dispensariam a elas, da forma em que as ajudam a responder às situações adversas da vida.

\section{PROCEDIMENTO METODOLÓGICO}

\section{O Paradigma: Um convite para o "pensamento complexo"}

O objeto da pesquisa, concebido enquanto ser - ser humano - dinâmico, movimento, que está lançado - agindo e interagindo - na fluidez da existência (CRITELLI, 1996), pedia um modelo que repetisse tal dinamismo. Um convite para um "pensamento complexo", explicitado por MORIN (1996).

O modelo que buscávamos deveria possibilitar-nos a organização e apresentação do material empírico coletado e analisado: entrevistas abertas e semi-estruturadas (DAMERGIAN, 1981), gravadas pelo pesquisador; fotografias (MAGNI, 1995/1996); registros no Diário de Campo (QUIVY \& CAMPENHOUDT, 1992) e técnicas de observação (SCHWARTZ, 1993) da moradia e do modo de morar, do complexo fenômeno dos moradores e exmoradores de rua e seu cotidiano; das circunstâncias (ORTEGA Y GASSET, 1989) que os envolviam; dos seus diálogos com as circunstâncias, ou seja, suas interações ou transações com esse entorno ou contorno - compreendido esse entorno não só no seu aspecto ambiental, de natureza, no seu modo de habitar o mundo, como também nas trocas - biopsico-socioafetivas - com os outros seres humanos do seu relacional.

Com o modelo do "complexos" (MORIN, 1996) em mente, optamos pela organização do material empírico coletado:

"Complexus é o que está junto; é o tecido formado por diferentes fios que se transformaram numa só coisa, isto é, tudo isso se entrecruza, tudo se entrelaça para formar a unidade da complexidade; porém, a unidade do complexos não destrói a variedade e diversidade das complexidades que o teceram.' (p. 188).

\section{Entretecendo a forma... dos "f os" da lingua- gem não cindida}

A linguagem buscou refletir a complexidade, a concepção de um ser humano não cindido "cartesianamente" em razão e emoção: linguagem não cindida, plena em seus recursos de expres- são, comportando, inclusive, o uso de adjetivos, metáforas, que foram necessários à apresentação do fenômeno.

Os "diferentes fios" revelados foram "entrecruzados" num primeiro momento, entrelaçados num "complexas", formando a primeira unidade de sentido.

O tipo de abordagem adotado para a interpretação dos dados pressupõe, portanto, o recurso de conceitos pertinentes às teorias da psicologia, da antropologia, da geografia e da sociologia no pressuposto de que a visão interdisciplinar (ALVARENGA, 1997) ou transdisciplinar (ALMEIDA FILHO, 1997; MORIN, 1996) permite uma leitura mais aproximada do objeto em questão.

Nesta perspectiva, o ponto de partida é a assunção da idéia básica defendida por MORIN (1996), da complexidade do objeto. Neste particular, abordagens da linha fenomenológica e etnográfico, assim como o próprio recurso da filosofia da existência apresentam-se como instrumental teórico-metodológico de grande relevância para o processo de análise deste estudo.

Assim, trata-se da tentativa de estabelecer um diálogo entre diferentes disciplinas do campo das ciências humanas, tendo em vista melhor apreender os significados.

\section{O REVELAR DAS FALAS}

\section{O sentido da vida. Quando o sentido se evade}

Os sujeitos relataram experiências de quebra dos nexos da existência, com a evasão do sentido de suas vidas. Sentiram-se caídos no vazio, na experiência da angústia face à inospitabilidade do mundo. Tornaram-se moradores de rua.

"Me esqueci de viver depois que perdi essa menina...” (Neilton)

\section{Exaustão: ódio da sociedade. Quase no crime}

Nessa trajetória do morar na rua, os sujeitos demonstraram momentos de profunda exaustão, denunciaram a discriminação e começaram a vivenciar um processo de ódio da sociedade que não os acolhia, quase entregando-se à criminalidade:

"Eu já tava vivendo... eu já tava querendo... meu coração já tava ficando maldoso, já, eu já tava percebendo que eu tava com maldade, também... porque eu já tava ficando com ódio da sociedade porque não dava uma chance, poxa, não procura pra conversar...” (Neilton)

5 “Entrecruzados”: no sentido de estabelecer relações. 


\section{O ponto fixo: um modelo favorável}

Um dos sujeitos demonstrou possuir identificação com uma relação amorosa, com urna mãe/pai/cuidador, com familiares do berço natal distantes que atuaram como modelos favoráveis, pontos fixos em sua vida infantil: ficaram-lhes os registros dos exemplos, das atitudes desses modelos:

"Eu ando de cabeça erguida mesmo! Eu acho lindo isso em mim! Aprendi com meu pai, digno mesmo!” (Neilton)

\section{Ausência de modelos favoráveis na infância}

Outros sujeitos demonstraram, em seus relatos, a ausência de trocas saudáveis, fundadas em uma relação amorosa, no período da infância. Denunciaram histórias de abandono por parte de figuras parentais:

"Mas meu pai mesmo, que era uma pessoa pra me dar apoio, que era o responsável por mim, ele me largou! ... Ele casou de novo; eu com a mulher dele, nois dois não 'bate', nóis dois se 'tromba'... e eu escolhi o mundo! Fui pra rua... aos treze anos...” (Hélio).

\section{Ponto fixo dos adultos: A criança}

Hélio consegue dar ao filho o que não teve da sua família: apoio, carinho, promover a “maternagem”(WINNICOTT, 1988) ${ }^{6}$ e "paternagem” de seu bebê, que fora abandonado pela própria mãe. A criança passa a ser-lhe um ponto fixo, ponto de apoio no seu reerguimento para uma forma mais saudável de vida: consegue sair da situação de morador de rua. O mesmo acontece com Neilton, que também cuida do pequeno Lino, ajudando o pai no sistema de cuidados ao bebê (de quem acaba se tornando padrinho de batismo):

“Ah, é o Linozinho... esse aqui é tudo pra mim!” (Hélio, o pai).

"Linozinho é importante na minha vida... Ele é um herói...” (Neilton).

\section{O trabalho como ponto fixo}

$\mathrm{Na}$ mesma direção explicitada por FRANKL (1989), como algo que possa auxiliar na auto transcendência da existência humana, temos o "trabalho" como um ponto fixo buscado, desejado ativamente pelos sujeitos:
"Eu quero vender alguma coisa... pra poder sobreviver, porque a gente ficar só nessa vida, não dá...” (“Cara Queimada”).

"Dignidade pra mim é o cara digno de trabalhar... Dando pra sobreviver, pôxa, pára com isso! (pára de pedir esmolas)” (Neilton).

SINGER (1996) observa que um quarto da mão de obra ocupada em áreas urbanas gostaria de ter um emprego formal. Este desejo está revelado na fala de Neilton, ao entender como trabalho a atividade que seja "fixa" ou formalizada, em vínculos estáveis:

"Eu faço um bico com ele, eu trabalho, num posso dizer que é um trabalho porque não é fixo, mas é o meu ganha pão, pelo menos eu sei que sou orgulhoso sobre isso, eu gosto de comer do que é do meu suor.” (Neilton).

\section{A vergonha}

ERIKSON (1976) relata que os adultos, inclusive os aparentemente maduros e não neuróticos, mostram-se muito sensíveis à possibilidade de um "vergonhoso descrédito". Ao abordar a manifestação desse sentimento, ele coloca que a vergonha se manifesta logo por um "impulso de esconder o rosto ou de, no mesmo instante e lugar, afundar no chão”.

"Eu fiquei um ano que ninguém sabia que eu tava vivo..."

“Eu disse: 'Eu estava viajando pra fora...' - e era mentira, estava em São Paulo mesmo... (morando na rua)” (José). loucura...

"Crack": a "pedra “... desagregação e

Pudemos acompanhar, dado o caráter de estudo longitudinal deste trabalho - ao longo de cinco anos - o advento e aumento do uso do “crack", a "pedra”, conforme os moradores de rua a denominam. Reconhecem seu caráter profundamente mórbido; tentam, por vezes, fazer resistência ao seu uso mas, devido ao "modo de morar” na rua, com suas práticas e relações específicas, fica difícil resistir a ela, conforme podemos acompanhar em seus relatos:

“... a maioria, uns 70\% dali é pra usar droga (referindo-se à malaca)... e é obrigado, porque se tem 25 ali e 10 usa droga, os quinze que não usa, é capaz até daqueles matar o outro, porque eles tem que aceitar aquilo. Então, o meu sofri-

6 WINNICOTT (1988) observa a importância do “contorno”, das primeiras relações da criança com o ambiente, do que ele chama de "maternagem suficientemente boa”, dos cuidados iniciais oferecidos pela mãe e, ainda, pelo pai e demais faimiliares, como essenciais à formação do indivíduo. 
mento é esse: que eu nunca aceitei...” (José, exmorador de rua).

"Esse daí pode dizer que nasceu duas vezes! Por causa de quê? Por causa da "pedra”! A mãe trocava a "pedra” pelo filho! ("Cara Queimada, ao referir-se ao menino Lino)

\section{A "mãe-sociedade filicida"}

DAMERGIAN (1988), ao explicitar sua crença de que a mãe-sociedade também deve funcionar como um ponto fixo para o desenvolvimento dos seus filhos membros, aponta a "destrutividade crescente, a falta de consideração pelo humano, a ausência de cooperação, as relações nada amorosas entre os seres humanos" respondendo a respeito de que "ponto fixo" tal sociedade nos oferece: o que predomina é o componente destrutivo. A este ponto acrescentamos a questão da "violência sistêmica social" referida por MINAYO (1997), que grassaria em nosso meio social e, entre vários arbítrios, chacinas, maus tratos, corrupção, assinala as dificuldades de grande parte da população de reconhecerem os direitos humanos como sendo seus próprios direitos.

"A gente vê muita desigualdade social, meu Deus... Hoje em dia a gente pode até desabafar, que eu antigamente lava falando isso daqui eu podia até ir pra cadeia, certo? Se vê os cara roubando na sua cara, anda tudo de gravata... e eu, só porque sou trabalhador, de vez em quando sou parado pela policia!” (Neilton).

\section{A sociedade como ponto fixo}

Estava instalada, nos sujeitos, a falta, a carência do sentimento positivo da confiança (ERIKSON, 1976). Era necessário o restabelecimento desse sentimento positivo, para que o sujeito pudesse novamente "olhar-se", "reconhecerse" como sujeito desejante, como ser humano. É quando lhe chega o ponto fixo, o "seio bom" portador do alimento necessário que lhe sacia a fome de confiança:

“... incentivo é incentivo... Eu quando conheci a dona Sílvia, eu tava numa situação com frio...”

"No meu caso, só a palavra amiga dela é muita coisa..." (Neilton, falando a respeito de Dona Silvia, que auxilia os moradores de rua).

Fontes de resiliência: "TENHO, SOU/ESTOU, POSSO”.
As falas dos sujeitos sociais deste estudo adultos moradores e ex-moradores de rua - revelaram-nos possuidores das mesmas características que GROTBERG (1996) observou nas crianças resilientes: tenho, sou/estou, posso. Se não todas, pelo menos algumas, em cada um deles. Observamos, portanto, a pertinência da utilização do mesmo referencial analítico/teórico neste estudo.

\section{A CIRCULARIDADE: REFLETINDO O RUMO...}

Acreditamos que - face aos conteúdos desvelados nas falas, aos registros do cotidiano do morar na rua e no barraco de um dos sujeitos, aos acontecimentos descritos e vividos pelo pesquisador (HO, 1998; MORIN, 1996) ${ }^{7}$, aos registros fotográficos e às reflexões teóricas feitas a partir da aparência do fenômeno e, mais, face ao desafio de pensar a "complexidade" conscientes de que o pensamento complexo comporta um princípio de incompletude e incerteza - possamos dizer:

O modo de morar nas ruas, na modalidade "selvagens urbanos", ainda que possa ter sido eleito em anos anteriores por alguns segmentos da população urbana como um modus vivendi, ou que essas pessoas tenham "caído" nesse modo de viver, sem opção, atualmente devido ao advento e aumento do consumo de drogas, notadamente o "crack”, por grande parte dessa população; às violências e doenças de todo tipo a que estão sujeitos, inclusive com o comprometimento de sua saúde mental - caractenza-se como fator de risco para as pessoas que vivem nessas condições.

Os sujeitos estudados, através de suas falas recolhidas em entrevistas ou na espontaneidade do seu viver em situação de rua, no seu cotidiano, demonstraram o desejo de buscar um outro modo de vida.

Alguns sujeitos, considerados hipoteticamente resilientes no início deste trabalho: Hélio e seu filho, o menino Lino; José; Neilton e "Cara Queimada, foram identificados como resilientes, ou seja, ante a quebra do sentido de suas existências - vivendo em situações de vida extremamente adversas - vivenciaram a angústia da inospitabilidade de suas vidas e não se deixaram sucumbir. Impulsionados pela "vontade de vida', com o auxílio de "pontos fixos" provenientes do entorno,

7 “O investigador não opera num vazio e, conseqüentemente, o conhecimento psicológico não é gerado independentemente do investigador.” (HO, 1998). MORISCA, 1996), a respeito do mesmo processo, propõe que o observador conceptor deve se Integrar na sua observação e na sua concepção. 
de “pontos fixos" internos representados por modelos saudáveis introjetados na infância distante ou de "maternagens tardias", com "seios bons" provenientes de "adultos amorosos" que os socorreram, puderam empreender a "viagem heróica” em busca de um novo sentido em suas vidas. Lançaram os seus “barcos” na fluidez da existên- cia, confiaram na dinâmica do viver. E acreditamos, neste momento, que possamos dizer, utilizando-nos de recurso metafónco evocativo do processo dinâmico do viver, que resiliência é isso: "uma dança bem sucedida na música da vida. Não uma dança com bailannos solitános: ela pede parcenas, empatia, encontros. Ela fala de amor”.

\begin{abstract}
The present work consisted in applying the category Resilience to the study of exhomeless of the central arca of São Paulo that searched for another way of living, in the sense of acknowledging the contribution that this concept can give to the equation of health actions, particularly of mental health, directed to homeless population in the context of Brazilian big cities. In this case study, four adults and one child egressed from a group of homeless of a central arca of São Paulo city were selected. From the investigato^ly point of view, they were considered as possible resilients, that is, carriers of the human capacity of coping with life adversities, of overcoming them and of getting out of them strengthened or even transformed. Based on open and semi-structured interviews, photographs, field diaries and observation techniques, an ethnographical description of housing was accomplished, as well as a description of the subjects' present and previous way of living, their psychological characteristics and their interaction with the environment in which they were living or lived before. Based on their trajectory, these subjects were positively considered as resilients, with the help of the heuristic concepts of "search for meaning” and internal and external "fixed points", which were identified in the subjects. Finally, the importance of the concept of resilience in studies of this nature is stressed, not to mention the need of diffusion for its effective application to the arca of Public Health.
\end{abstract}

Key-words: Resilience; homeless; mental health; Public Health.

\section{REFERÊNCIAS BIBLIOGRÁFICAS}

ALMEIDA FILHO, N. Transdisciplinaridade e saúde coletiva. Cienc. Saúde Coletiva, 2: 520, 1997.

ALVARENGA, A. T. Considerações teórico-metodológicas acerca do discurso de Naomar de Almeida Filho sobre "transdisciplinaridade e saúde coletiva”. Cienc. Saúde Coletiva, 2: 4552, 1997.

ALVAREZ, A. M. S. Nasceu uma criança na "sarjeta”: e agora? Rev. Bras. Cresc. Des. Hum., 4(2): 69-73, 1994.

ALVAREZ, A. M. S., MORAES, M. C. L., RABINOVICH, E. P. Resiliência: um estudo com brasileiros institucionalizados. In: 49a Reunião Anual da SBPC, Belo Horizonte, 1997. Anais, Belo Horizonte, SBPC, 1997. p. 888-889.

BOWLBY, J. Apego. São Paulo, Martins Fontes, 1990.

BOWLBY, J. Uma base segura: aplicações clínicas da teoria do apego. Porto Alegre, Artes Médicas, 1989.

CRITELLI, D. M. Analítica do sentido: uma aproximação e interpretação do real de orientação fenomenológica. São Paulo, EDUC/Brasiliense, 1996.
DAMERGIAN, S. O papel do inconsciente na interação humana: um estudo sobre o objeto da psicologia social. São Paulo,1988. [TesedeDoutorado-Instituto de Psicologia da Universidade de São Paulo].

DAMERGIAN, S. A fala regional e o contexto social: um estudo sobre como são recebidos os falantes que se utilizam do português nãopadrão nordestino em um contexto onde só o português padrão é admitido. São Paulo; 1981. [Dissertação de Mestrado - Instituto de Psicologia da Universidade de São Paulo].

ERIKSON, E. H. Infância e sociedade. Rio de Janeiro, Zahar, 1976.

FRANKL, V. E. Um sentido para a vida: psicoterapia e humanismo. São Paulo, Editora Santuário, 1989.

GROTBERG, E. H. Guia de promoción de la resiliencia en los niños para fortalecer el espirito humano. La Haya, Fundación Bernardvan Leer, 1996. (Informes de Trabajo sobre el Desarrollo de la Primera Infancia, 18).

HO, D. Y. F. Indigenous psychologies: Asian perspectives. J. Cross-Cult. Psychol., 29(1): 88-103, 1998.

KLEIN, M. O sentimento de solidão. Rio de Janeiro, Imago, 1971. 
MAGNI, C. T. Povo da rua: um estudo sobre o nomadismo urbano. Coleção Cadernos da Cidade, 4(2) 1-41, 1995.

MAGNI, C. T. Em busca do nomadismo da imagem. In: $20^{\mathrm{a}}$ Reunião Brasileira de Antropologia, Salvador, 1996. [mimeo].

MINAYO, M. C. S. Violência, direitos humanos e saúde. In: CANESQUI, A. M. (org.). Ciências sociais e saúde. São Paulo, HUCITEC/ ABRASCO, 1997. p. 247-258.

MORIN, E. Ciência com consciência. Rio de Janeiro, Bertrand do Brasil, 1996.

ORTEGA Y GASSET, J. Em torno a Galileu: esquema das crises. Petrópolis, Vozes, 1989.

QUIW, R.; CAMPENHOUDT, L. V. Manual de investigações em ciências sociais. Lisboa, Gradiva, 1992.
RABINOVICH, E. P. Vitrinespelhos transicionais da identidade: um estudo de moradias e do ornamental em espaços sociais liminares brasileiros. São Paulo, 1996. [Tese de Doutorado - Instituto de Psicologia da Universidade de São Paulo].

SCHWARTZ, O. L'empirisme irréductible. In: ANDERSON, N. Le bobo: sociologia dá sans abri. Paris, Nathan, 1993. p. 265-305. (Collection Essais et Recherches).

SINGER, P. Um mapa da exclusão social no Brasil. In: SINGER, P. et al. Modernidade: globalização e exclusão. São Paulo, Editora Imaginário, 1996. p. 75-113.

WINNICOTT, D. W. Os bebês e suas mães. São Paulo, Martins Fontes, 1988. 